\title{
Risk factors for cardiovascular disease in women with diabetes
}

\author{
Christine Maric \\ Department of Physiology and Biophysics, The Center for Excellence in Cardiovascular and \\ Renal Research and the Women's Health Research Center, University of Mississippi Medical \\ Center, Jackson, MS
}

\section{Keywords}

Estrogens; hyperglycemia; dyslipidemia; obesity; hypertension; sex hormones; heart

Cardiovascular disease (CVD) is a well recognized complication of type 2 diabetes in both men and women ${ }^{1-2}$. A large number of studies have shown evidence of increased risk for CVD in patients with type 2 diabetes compared with the general population ${ }^{3-6}$ and that this increased relative risk for CVD due to diabetes is greater in women than men. Interestingly, while mortality due to CVD appears to be declining in both the general population and in patients with type 2 diabetes ${ }^{7}$, it remains controversial whether this decline in seen in both men and women. Indeed, analysis of the National Health and Nutrition Examination Survey (NHANES) suggested that the decline in all-cause mortality have occurred among men with diabetes, but not in women ${ }^{8}$. In patients with type 2 diabetes, some studies have reported greater mortality due to CVD in women compared with men ${ }^{9-12}$ while others show higher mortality in men ${ }^{13}$. A recent analysis of the Framingham Heart study reported no sex differences in CVD mortality in patients with type 2 diabetes ${ }^{2,14}$. Similarly divergent are the data in patients with type 1 diabetes in which mortality from CVD has either been shown to be either higher in women ${ }^{3,15}$, higher in men ${ }^{16}$ or not different between the sexes ${ }^{17-19}$. Even though many of these conflicting findings are likely due to differences in study methodologies, it stresses the importance of examining the risk factors that contribute to the risk for CVD and its associated mortality in men and women separately.

Sex differences, or lack thereof, in the risk for CVD and its associated morbidity and mortality in patients with type 2 diabetes may be explained through sex differences in several common risk factors. These include, but are not limited to hyperglycemia, dyslipidemia and hypertension. While there has been a general trend in the improvements in some of these CVD risk factors as well as in advances in their prevention and treatment over the recent years, whether these improvements are seen both in women and men remains controversial.

In the current issue of Gender Medicine, Göbl et al present a study that examined sex differences in glycemic control, dyslipidemia and blood pressure in a Central European population of insulin treated patients with type 2 diabetes. The major findings of this study are: 1 . women with type 2 diabetes have higher levels of LDL-cholesterol, HDL-cholesterol, systolic and diastolic blood pressure compared with age-matched men with type 2 diabetes; 2. No differences in HbA1c are observed between men and women with type 2 diabetes; 3 . women have a higher chance to fail treatment goals in blood pressure but not in cholesterol

Correspondence to: Christine Maric, PhD, Department of Physiology and Biophysics, University of Mississippi Medical Center, 2500 North State Street, Jackson, MS 39216, Phone: 601-984-1818; Fax: 601-984-1817, cmaric@umc.edu. 
and $\mathrm{HbA} 1 \mathrm{c}$ levels. The authors conclude that women with type 2 diabetes have a more adverse cardiovascular risk factor profile than men, despite similar glycemic control.

Type 2 diabetes is a disease associated with chronically increased blood glucose levels as a result of both insulin deficiency and insulin resistance. Higher levels and wide fluctuations in fasting blood glucose, 2-hour postprandial blood glucose or HbA1c are characteristic of patients with type 2 diabetes, and these contribute to the development of microvascular and microvascular complications ${ }^{20-23}$. However, little is known whether these variations in glucose levels or HbA1c differ between women and men with type 2 diabetes and how this may impact their risk for CVD. The few studies that have in fact directly examined sex differences in blood glucose levels and glycemic control in patients with type 2 diabetes report better glycemic control in men than women. A cross-sectional analysis including 3,849 patients with type 2 diabetes found that women, whether or not they had CVD were less likely than men to have $\mathrm{HbA}(1 \mathrm{c})<7 \%{ }^{24}$. The prospective, Rancho Bernardo study showed that post-challenge hyperglycemia increases the risk for CVD more in women than men ${ }^{25}$. Similarly, in the San Antonio Heart Study, hyperglycemia was associated with increased CVD mortality more so in women than men ${ }^{26}$. The fact that hyperglycemia is more common in women than men may be somewhat surprising given the beneficial effects of estrogens on hyperglycemia by promoting insulin secretion ${ }^{27-28}$ and reducing the incidence of type 2 diabetes itself ${ }^{29-30}$. However, studies have shown that estrogen levels decline in women with type 2 diabetes even before menopause ${ }^{31-32}$, suggesting that the loss of the female sex as a protective factor against the development of CVD in type 2 diabetes may, in part, be explained through the decline in estrogen levels and therefore loss of the estrogen-induced insulin secretion.

The term "dyslipidemia" is commonly used to describe the disorder of lipoprotein metabolism, including lipoprotein overproduction or deficiency. Low HDL cholesterol, and high triglycerides have been shown to contribute to the risk for CVD in type 2 diabetes in general, but more so in women than in men ${ }^{24,33}$. Interestingly, the present study by Göbl et al shows that women with type 2 diabetes exhibit higher levels of both LDL-cholesterol and HDL-cholesterol. The most likely explanation for this observation is that indeed, women more frequently have higher HDL levels than men and since elevated HDL levels are generally considered beneficial, women are less aggressively treated with lipid-lowering agents ${ }^{34}$. This lack in treatment in women could in turn lead to the observed elevated LDL levels as well. Interestingly though, since the consensus recommendations for treating elevated LDL levels are identical for men and women ${ }^{24}$, it is surprising then to see that LDL levels are still higher in women than men, as reported in the present study by Göbl et al. This observation may suggest that even if women are treated as aggressively as men for dyslipidemia that the efficacy of lipid-lowering agents differs between the sexes. Weather or not this indeed is true is hard to establish, since most of the studies examining the efficacy of lipid-lowering agents in type 2 diabetes have either only included men or have not examined the data in a sex-specific manner ${ }^{35-37}$. Only one study reported equal efficacy of rosuvastatin and other statins in lowering LDL levels in post-menopausal women compared with age-matched men ${ }^{38}$. However, the study grouped non-diabetic and diabetic women, making it difficult to draw any conclusions on whether or not statins are equally effective in men and women with type 2 diabetes. Another aspect to consider when analyzing the contribution of dyslipidemia to the risk for CVD is the notion that perhaps elevated HDL levels are not as protective in patients with type 2 diabetes as they are in non-diabetics ${ }^{39}$. If this indeed is the case, then higher levels in both HDL and LDL in women compared with men with type 2 diabetes would suggest an even greater risk for CVD in women than presently acknowledged. 
Type 2 diabetes and hypertension are in many ways interrelated diseases and both significantly increase the risk for CVD and lowering blood pressure has been shown to improve cardiovascular prognosis in patients with type 2 diabetes ${ }^{40-43}$. However, whether there are sex differences in blood pressure levels in patients with type 2 and to what degree these differences may alter the risk for CVD is controversial. The present study by Göbl et al shows that women with type 2 diabetes have higher systolic as ell as diastolic blood pressure. Furthermore, the study concludes that women have a greater chance of failing therapeutic goals for treatment of their blood pressure. Similar observations were made by others $24,44-45$. These observations are somewhat surprising given that in non-diabetic women, blood pressure levels are lower compared with age-matched non-diabetic men, at least until menopause ${ }^{46-48}$. This observation suggests that diabetes eliminates the protective effect of the female sex with respect to hypertension. The observation by Göbl et al also that women with type 2 diabetes have a greater chance of failing therapeutic goals for treatment of their blood pressure is also somewhat surprising given that in general, women are more compliant than men regarding taking medication. There are several possible explanations for the observed failure to achieve therapeutic goals in women: 1 . that women with type 2 diabetes are not being diagnosed with high blood pressure or treated as aggressively as men with type 2 diabetes; 2 . That the medication used to treat high blood pressure is not as effective in women as in men; 3 . That the pathophysiology of hypertension is different in men and women and thus the targets being treated are missed with existing/conventional therapy. It is likely that the actual truth lies in all of these explanations, underscoring the importance of examining the pathophysiology of hypertension associated with type 2 diabetes in a sex-specific manner.

Even though the present study by Göbl et al did not directly examine the contribution of obesity on the risk for CVD, a few words should be added about the potential contribution of obesity, either as a direct risk for CVD or an indirect risk, via contributing to the onset of type 2 diabetes. It is well established that visceral obesity poses a much greater risk for CVD than subcutaneous adiposity, which is why pre-menopausal women use to be considered to have a lower risk of obesity-related disorders, including CVD ${ }^{49-50}$. However, with the epidemic of obesity and its associated cardiometabolic complications, obese women no longer hold the advantage over men when it comes to development of CVD. In fact, evidence suggests that visceral adiposity in obese women increases the risk for CVD to a much greater extent than in men ${ }^{51-52}$. This observation may be surprising given that adipose tissue is a known source of estrogens which, in turn, have known cardioprotective effects ${ }^{53-56}$. This suggests that estrogens, depending on their source and whether their action is paracrine or endocrine, may exert beneficial as well as detrimental effects on target organs.

Increasing evidence suggests that diabetes is a state of an imbalance in sex hormone levels. In particular, women with type 2 diabetes commonly exhibit increases in circulating testosterone alongside decreases in estradiol levels ${ }^{31-32,57}$. In essence, this perturbation in hormone levels in women results in a hormonal profile that resembles that of a man, with a higher testosterone/estrogen ratio. This perturbation may be one of the likely explanations as to why in the setting of diabetes, the female sex as a protective factor against CVD appears to be diminished. Based on this assumption, it would be reasonable to think that hormone supplementation to restore the normal testosterone/estrogen ratio would be beneficial in women with type 2 diabetes with CVD complications. Indeed, a few studies have shown that hormone therapy in women with type 2 diabetes is associated with a reduction in visceral adiposity and improvement in lipid and glucose metabolism, all of which are risk factor of CVD ${ }^{58-60}$. While the precise mechanisms by which sex hormones exert their effects and contribute to development of CVD are still being investigated, both clinical and experimental studies suggest that sex hormones are important regulators of fat, glucose and 
lipid metabolism, blood pressure, cardiovascular and renal function ${ }^{55-56,61-64}$. In essence, sex hormones may be important regulators of multiple biological processes, dysfunction of which may contribute to the risk for CVD.

In conclusion, the study by Göbl et al confirm previous reports that women with type 2 diabetes are at a greater relative risk for developing CVD than age-matched men. The fact that this sexual disparity exists despite comparable glycemic control suggests that other pathophysiological mechanisms may contribute to this increased risk of CVD in women with type 2 diabetes. Based on current evidence, it is apparent that presentation and diagnosis of CVD differs in women and men with type 2 diabetes and thus the method and timing of treatment should be sex-specific. Finally, additional clinical studies examining the factors contributing to the risk of CVD in women with type 2 diabetes are warranted.

\section{Acknowledgments}

Source of funding: None

\section{References}

1. Fox CS, Coady S, Sorlie PD, et al. Trends in cardiovascular complications of diabetes. JAMA. 2004; 292:2495-2499. [PubMed: 15562129]

2. Preis SR, Hwang SJ, Coady S, et al. Trends in all-cause and cardiovascular disease mortality among women and men with and without diabetes mellitus in the Framingham Heart Study, 1950 to 2005. Circulation. 2009; 119:1728-1735. [PubMed: 19307472]

3. Allemann S, Saner C, Zwahlen M, Christ ER, Diem P, Stettler C. Long-term cardiovascular and non-cardiovascular mortality in women and men with type 1 and type 2 diabetes mellitus: a 30-year follow-up in Switzerland. Swiss Med Wkly. 2009; 139:576-583. [PubMed: 19838876]

4. Kannel WB, McGee DL. Diabetes and cardiovascular disease. The Framingham study. JAMA. 1979; 241:2035-2038. [PubMed: 430798]

5. Hillege HL, Fidler V, Diercks GF, et al. Urinary albumin excretion predicts cardiovascular and noncardiovascular mortality in general population. Circulation. 2002; 106:1777-1782. [PubMed: 12356629]

6. de Zeeuw D, Parving HH, Henning RH. Microalbuminuria as an early marker for cardiovascular disease. J Am Soc Nephrol. 2006; 17:2100-2105. [PubMed: 16825327]

7. Dale AC, Vatten LJ, Nilsen TI, Midthjell K, Wiseth R. Secular decline in mortality from coronary heart disease in adults with diabetes mellitus: cohort study. BMJ. 2008; 337:a236. [PubMed: 18595902]

8. Gregg EW, Gu Q, Cheng YJ, Narayan KM, Cowie CC. Mortality trends in men and women with diabetes, 1971 to 2000. Ann Intern Med. 2007; 147:149-155. [PubMed: 17576993]

9. Barrett-Connor E, Ensrud KE, Harper K, et al. Post hoc analysis of data from the Multiple Outcomes of Raloxifene Evaluation (MORE) trial on the effects of three years of raloxifene treatment on glycemic control and cardiovascular disease risk factors in women with and without type 2 diabetes. Clin Ther. 2003; 25:919-930. [PubMed: 12852708]

10. Morgan CL, Currie CJ, Peters JR. Relationship between diabetes and mortality: a population study using record linkage. Diabetes Care. 2000; 23:1103-1107. [PubMed: 10937505]

11. Dawson SI, Willis J, Florkowski CM, Scott RS. Cause-specific mortality in insulin-treated diabetic patients: a 20-year follow-up. Diabetes Res Clin Pract. 2008; 80:16-23. [PubMed: 18329124]

12. Szalat A, Raz I. Gender-specific care of diabetes mellitus: particular considerations in the management of diabetic women. Diabetes Obes Metab. 2008; 10:1135-1156. [PubMed: 18494812]

13. Krolewski AS, Czyzyk A, Janeczko D, Kopczynski J. Mortality from cardiovascular diseases among diabetics. Diabetologia. 1977; 13:345-350. [PubMed: 913925] 
14. Preis SR, Pencina MJ, Hwang SJ, et al. Trends in cardiovascular disease risk factors in individuals with and without diabetes mellitus in the Framingham Heart Study. Circulation. 2009; 120:212220. [PubMed: 19581493]

15. Laing SP, Swerdlow AJ, Slater SD, et al. Mortality from heart disease in a cohort of 23,000 patients with insulin-treated diabetes. Diabetologia. 2003; 46:760-765. [PubMed: 12774166]

16. Dorman JS, Laporte RE, Kuller LH, et al. The Pittsburgh insulin-dependent diabetes mellitus (IDDM) morbidity and mortality study. Mortality results. Diabetes. 1984; 33:271-276. [PubMed: 6698317]

17. Skrivarhaug T, Bangstad HJ, Stene LC, Sandvik L, Hanssen KF, Joner G. Long-term mortality in a nationwide cohort of childhood-onset type 1 diabetic patients in Norway. Diabetologia. 2006; 49:298-305. [PubMed: 16365724]

18. Waernbaum I, Blohme G, Ostman J, et al. Excess mortality in incident cases of diabetes mellitus aged 15 to 34 years at diagnosis: a population-based study (DISS) in Sweden. Diabetologia. 2006; 49:653-659. [PubMed: 16447054]

19. Berger B, Stenstrom G, Sundkvist G. Incidence, prevalence, and mortality of diabetes in a large population. A report from the Skaraborg Diabetes Registry. Diabetes Care. 1999; 22:773-778. [PubMed: 10332680]

20. Yu PC, Bosnyak Z, Ceriello A. The importance of glycated haemoglobin $(\mathrm{HbA}(1 \mathrm{c}))$ and postprandial glucose (PPG) control on cardiovascular outcomes in patients with type 2 diabetes. Diabetes Res Clin Pract. 2010; 89:1-9. [PubMed: 20494468]

21. Nalysnyk L, Hernandez-Medina M, Krishnarajah G. Glycaemic variability and complications in patients with diabetes mellitus: evidence from a systematic review of the literature. Diabetes Obes Metab. 2010; 12:288-298. [PubMed: 20380649]

22. Barrett-Connor E, Giardina EG, Gitt AK, Gudat U, Steinberg HO, Tschoepe D. Women and heart disease: the role of diabetes and hyperglycemia. Arch Intern Med. 2004; 164:934-942. [PubMed: 15136300]

23. Laakso M. Hyperglycemia as a risk factor for cardiovascular disease in type 2 diabetes. Prim Care. 1999; 26:829-839. [PubMed: 10523462]

24. Wexler DJ, Grant RW, Meigs JB, Nathan DM, Cagliero E. Sex disparities in treatment of cardiac risk factors in patients with type 2 diabetes. Diabetes Care. 2005; 28:514-520. [PubMed: 15735180]

25. Barrett-Connor E, Ferrara A. Isolated postchallenge hyperglycemia and the risk of fatal cardiovascular disease in older women and men. The Rancho Bernardo Study. Diabetes Care. 1998; 21:1236-1239. [PubMed: 9702426]

26. Wei M, Gaskill SP, Haffner SM, Stern MP. Effects of diabetes and level of glycemia on all-cause and cardiovascular mortality. The San Antonio Heart Study. Diabetes Care. 1998; 21:1167-1172. [PubMed: 9653614]

27. Le May C, Chu K, Hu M, et al. Estrogens protect pancreatic beta-cells from apoptosis and prevent insulin-deficient diabetes mellitus in mice. Proc Natl Acad Sci U S A. 2006; 103:9232-9237. [PubMed: 16754860]

28. Yamabe N, Kang KS, Zhu BT. Beneficial effect of 17beta-estradiol on hyperglycemia and islet beta-cell functions in a streptozotocin-induced diabetic rat model. Toxicol Appl Pharmacol. Aug 27.2010 [Epub ahead of print].

29. Kanaya AM, Herrington D, Vittinghoff E, et al. Glycemic effects of postmenopausal hormone therapy: the Heart and Estrogen/progestin Replacement Study. A randomized, double-blind, placebo-controlled trial. Ann Intern Med. 2003; 138:1-9. [PubMed: 12513038]

30. Margolis KL, Bonds DE, Rodabough RJ, et al. Effect of oestrogen plus progestin on the incidence of diabetes in postmenopausal women: results from the Women's Health Initiative Hormone Trial. Diabetologia. 2004; 47:1175-1187. [PubMed: 15252707]

31. Stamataki KE, Spina J, Rangou DB, Chlouverakis CS, Piaditis GP. Ovarian function in women with non-insulin dependent diabetes mellitus. Clin Endocrinol (Oxf). 1996; 45:615-621. [PubMed: 8977760] 
32. Ding EL, Song Y, Malik VS, Liu S. Sex differences of endogenous sex hormones and risk of type 2 diabetes: a systematic review and meta-analysis. JAMA. 2006; 295:1288-1299. [PubMed: 16537739]

33. Juutilainen A, Kortelainen S, Lehto S, Ronnemaa T, Pyorala K, Laakso M. Gender difference in the impact of type 2 diabetes on coronary heart disease risk. Diabetes Care. 2004; 27:2898-2904. [PubMed: 15562204]

34. O’Meara JG, Kardia SL, Armon JJ, Brown CA, Boerwinkle E, Turner ST. Ethnic and sex differences in the prevalence, treatment, and control of dyslipidemia among hypertensive adults in the GENOA study. Arch Intern Med. 2004; 164:1313-1318. [PubMed: 15226165]

35. Bergenstal RM, Wysham C, Macconell L, et al. Efficacy and safety of exenatide once weekly versus sitagliptin or pioglitazone as an adjunct to metformin for treatment of type 2 diabetes (DURATION-2): a randomised trial. Lancet. 2010; 376:431-439. [PubMed: 20580422]

36. Fazio S, Guyton JR, Polis AB, et al. Long-term safety and efficacy of triple combination ezetimibe/simvastatin plus extended-release niacin in patients with hyperlipidemia. Am J Cardiol. 2010; 105:487-494. [PubMed: 20152243]

37. Farnier M, Ducobu J, Bryniarski L. Efficacy and safety of adding fenofibrate $160 \mathrm{mg}$ in high-risk patients with mixed hyperlipidemia not controlled by pravastatin $40 \mathrm{mg}$ monotherapy. Am J Cardiol. 2010; 106:787-792. [PubMed: 20816118]

38. Blasetto JW, Stein EA, Brown WV, Chitra R, Raza A. Efficacy of rosuvastatin compared with other statins at selected starting doses in hypercholesterolemic patients and in special population groups. Am J Cardiol. 2003; 91:3C-10C. discussion 10C.

39. Gowri MS, Van der Westhuyzen DR, Bridges SR, Anderson JW. Decreased protection by HDL from poorly controlled type 2 diabetic subjects against LDL oxidation may Be due to the abnormal composition of HDL. Arterioscler Thromb Vasc Biol. 1999; 19:2226-2233. [PubMed: 10479666]

40. Mourad JJ, Le Jeune S. Blood pressure control, risk factors and cardiovascular prognosis in patients with diabetes: 30 years of progress. J Hypertens Suppl. 2008; 26:S7-13. [PubMed: 19363847]

41. Turnbull F, Neal B, Algert C, et al. Effects of different blood pressure-lowering regimens on major cardiovascular events in individuals with and without diabetes mellitus: results of prospectively designed overviews of randomized trials. Arch Intern Med. 2005; 165:1410-1419. [PubMed: 15983291]

42. Gaede P, Vedel P, Larsen N, Jensen GV, Parving HH, Pedersen O. Multifactorial intervention and cardiovascular disease in patients with type 2 diabetes. N Engl J Med. 2003; 348:383-393. [PubMed: 12556541]

43. Lindholm LH, Ibsen H, Dahlof B, et al. Cardiovascular morbidity and mortality in patients with diabetes in the Losartan Intervention For Endpoint reduction in hypertension study (LIFE): a randomised trial against atenolol. Lancet. 2002; 359:1004-1010. [PubMed: 11937179]

44. Nilsson PM, Theobald H, Journath G, Fritz T. Gender differences in risk factor control and treatment profile in diabetes: a study in 229 swedish primary health care centres. Scand J Prim Health Care. 2004; 22:27-31. [PubMed: 15119517]

45. Hypertension in Diabetes Study (HDS): I. Prevalence of hypertension in newly presenting type 2 diabetic patients and the association with risk factors for cardiovascular and diabetic complications. J Hypertens. 1993; 11:309-317. [PubMed: 8387089]

46. Ong KL, Cheung BM, Man YB, Lau CP, Lam KS. Prevalence, awareness, treatment, and control of hypertension among United States adults 1999-2004. Hypertension. 2007; 49:69-75. [PubMed: 17159087]

47. Vasan RS, Beiser A, Seshadri S, et al. Residual lifetime risk for developing hypertension in middle-aged women and men: The Framingham Heart Study. JAMA. 2002; 287:1003-1010. [PubMed: 11866648]

48. Lewington S, Clarke R, Qizilbash N, Peto R, Collins R. Age-specific relevance of usual blood pressure to vascular mortality: a meta-analysis of individual data for one million adults in 61 prospective studies. Lancet. 2002; 360:1903-1913. [PubMed: 12493255]

49. Shi H, Clegg DJ. Sex differences in the regulation of body weight. Physiol Behav. 2009; 97:199204. [PubMed: 19250944] 
50. Nedungadi TP, Clegg DJ. Sexual dimorphism in body fat distribution and risk for cardiovascular diseases. J Cardiovasc Transl Res. 2009; 2:321-327. [PubMed: 20560019]

51. Regitz-Zagrosek V, Lehmkuhl E, Mahmoodzadeh S. Gender aspects of the role of the metabolic syndrome as a risk factor for cardiovascular disease. Gend Med. 2007; 4 (Suppl B):S162-177. [PubMed: 18156101]

52. Olson MB, Shaw LJ, Kaizar EE, et al. Obesity distribution and reproductive hormone levels in women: a report from the NHLBI-sponsored WISE Study. J Womens Health (Larchmt). 2006; 15:836-842. [PubMed: 16999639]

53. Mendelsohn ME. Estrogen actions in the cardiovascular system. Climacteric. 2009; 12 (Suppl 1): 18-21. [PubMed: 19811235]

54. Vitale C, Mendelsohn ME, Rosano GM. Gender differences in the cardiovascular effect of sex hormones. Nat Rev Cardiol. 2009; 6:532-542. [PubMed: 19564884]

55. Duckles SP, Miller VM. Hormonal modulation of endothelial NO production. Pflugers Arch. 2010; 459:841-851. [PubMed: 20213497]

56. Dubey RK, Oparil S, Imthurn B, Jackson EK. Sex hormones and hypertension. Cardiovasc Res. 2002; 53:688-708. [PubMed: 11861040]

57. Lamon-Fava S, Barnett JB, Woods MN, et al. Differences in serum sex hormone and plasma lipid levels in Caucasian and African-American premenopausal women. J Clin Endocrinol Metab. 2005; 90:4516-4520. [PubMed: 15886254]

58. Cignarella A, Bolego C, Pinna C, Zanardo R, Eberini I, Puglisi L. The influence of sex hormones on vascular responses in the aorta of streptozotocin-diabetic male rats. Naunyn Schmiedebergs Arch Pharmacol. 2000; 361:514-520. [PubMed: 10832605]

59. Ferrara A, Karter AJ, Ackerson LM, Liu JY, Selby JV. Hormone replacement therapy is associated with better glycemic control in women with type 2 diabetes: The Northern California Kaiser Permanente Diabetes Registry. Diabetes Care. 2001; 24:1144-1150. [PubMed: 11423493]

60. Samaras K, Hayward CS, Sullivan D, Kelly RP, Campbell LV. Effects of postmenopausal hormone replacement therapy on central abdominal fat, glycemic control, lipid metabolism, and vascular factors in type 2 diabetes: a prospective study. Diabetes Care. 1999; 22:1401-1407. [PubMed: 10480500]

61. Khor VK, Dhir R, Yin X, Ahima RS, Song WC. Estrogen sulfotransferase regulates body fat and glucose homeostasis in female mice. Am J Physiol Endocrinol Metab. 2010; 299:E657-E664. [PubMed: 20682840]

62. Yepuru M, Eswaraka J, Kearbey JD, et al. Estrogen receptor-\{beta $\}$-selective ligands alleviate high-fat diet- and ovariectomy-induced obesity in mice. J Biol Chem. 2010; 285:31292-31303. [PubMed: 20657011]

63. Brown LM, Clegg DJ. Central effects of estradiol in the regulation of food intake, body weight, and adiposity. J Steroid Biochem Mol Biol. 2010; 122:65-73. [PubMed: 20035866]

64. Maric C, Sullivan S. Estrogens and the diabetic kidney. Gend Med. 2008; 5 (Suppl A):S103-S113. [PubMed: 18395675] 